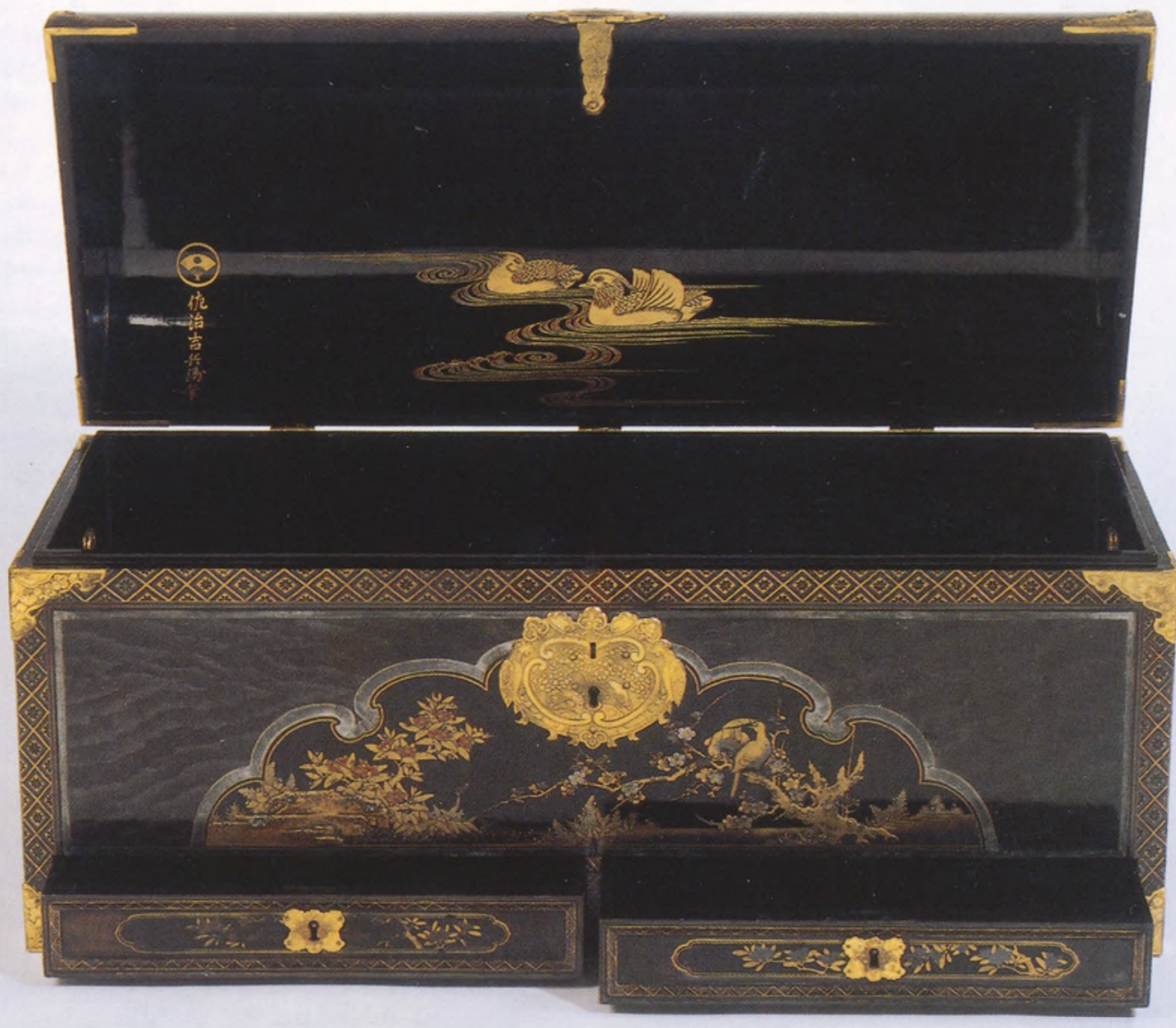

Afbeelding 1

Koffer vervaardigd en gesig-

neerd door Saji Kichibei,

circa 1650 , breedte $97,5 \mathrm{~cm}$.,

Groninger Museum. Uit:

Impey en Jörg (zie noot 1) 


\section{MACKIA KISEIJMON OF SIROSAIMON: WIE WAS DE 'MAKER' VAN DE LAKKOKER VAN HENDRIK VAN BUIJTENHEM?}

Een van de vragen over Japans export lakwerk waar nauwelijks antwoord op te geven is, is wie precies de voorwerpen hebben gemaakt. Op slechts enkele stukken is de naam van de lakwerker aangebracht. De bekendste naam is die van Sasaya: zijn naam is te vinden op een paar secrétaires (waarvan één zich in het Rijksmuseum bevindt) en aan aantal plaquettes met zeegevechten, waarop ook het jaartal 1792 is vermeld. ${ }^{1}$ Een koffer in het Groninger Museum is gesigneerd Kichibei, een naam die in verband wordt gebracht met een lakwerker Kitsibe, die in het dagregister van 1653/4, bijgehouden door het opperhoofd van de VOC-factorij in Japan, wordt genoemd. ${ }^{2}$

De veelsoortige documenten die de Verenigde Oost-Indische Compagnie ons heeft nagelaten, vormen samen een unieke bron over haar handel in Japans exportlakwerk. In deze documenten worden lakwerkers bij naam genoemd, maar het is niet mogelijk specifieke objecten aan hen toe te schrijven. In 1615 vinden we de eerste vermelding van de naam van een lakwerker: Luis-dono, mijnheer Luis, bij wie de Nederlanders kabinetjes hadden besteld. ${ }^{3}$ In het jaar daarop is er melding van Gengemon/Gingemon, Fanejemon/Fanjemon, Fatsemon/Fatsjemon die lakwerk voor de Compagnie maakten. ${ }^{4}$ In de jaren 30 van de $17^{\mathrm{e}}$ eeuw komen we enkele keren de naam Mahia Siemon tegen: in 1635 leverde hij in totaal 510 stuks lakwerk, bestaande uit comptoiren (kabinetten), koffers en kisten, aan de Compagnie. ${ }^{5}$ Een jaar later werden 619 stuks lakwerk afgerekend. ${ }^{6}$

In 1642 sloot opperhoofd Jan van Elseracq een contract met de lakwerker die in het verleden al stukken aan de Compagnie had geleverd. ${ }^{7}$ Het gaat om gewoon lakwerk zoals dat al eerder uit Japan naar Batavia was gestuurd en om 'extraordinarie rare ende costelijcke stucken'. ${ }^{8}$ Het jaar daarop bleek de aflevering van het bestelde lakwerk problemen op te leveren. Mackina Sinsemon, bij wie de bestelling in 1642 geplaatst was, had de stukken naar Nagasaki gebracht om ze aan de Nederlanders af te leveren. Maar lakwerkers uit Osaka, Miyako (de oude naam voor Kyoto) en Nagasaki beklaagden zich bij de gouverneur van Nagasaki dat slechts één man, de genoemde Mackina Sinsemon, al het lakwerk mocht leveren dat in 1642 was aanbesteed.

Het lakwerk dat zij hadden meegebracht, konden zij nu niet verkopen en ze verzochten de gouverneur om een meer gelijke verdeling te maken en toe te staan dat een ieder zijn waren ter verkoop mocht aanbieden voor de hoogste prijs die hij kon krijgen. Sinsemon werd vervolgens belet de gecontracteerde waren te voldoen, hetgeen hem een enorm verlies zou opleveren. Het conflict werd pas bijgelegd toen het Nederlandse opperhoofd dreigde dat de schepen zouden vertrekken zonder lakwerk als er bijtijds geen oplossing zou komen. ${ }^{9}$ 


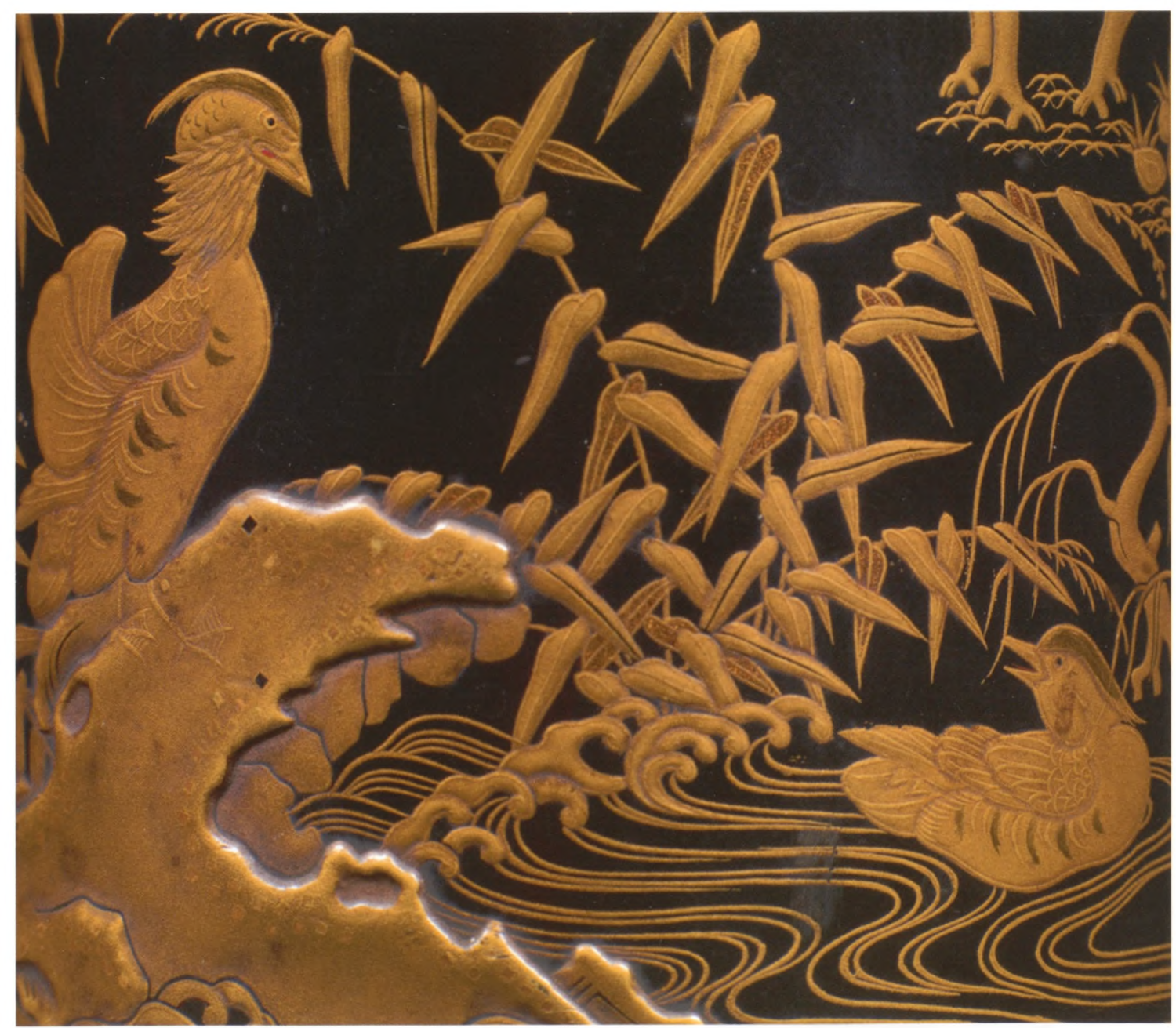

In 1652 had opperhoofd Frederik Coyett er meer dan genoeg van en hij probeerde te bewerkstelligen dat de Compagnie weer met één man zaken kon doen, zodat zij beter waar voor haar geld zou krijgen. Zijn verzoek hiertoe werd door de gouverneur geweigerd en Coyett besloot hierop geen lakwerk te bestellen. ${ }^{10}$ Herhaalde pogingen om slechts met de meester-lakwerkers zaken te mogen doen, liepen in de daaropvolgende jaren echter steeds op niets uit. Maar omdat het voor de Compagnie van groot belang was dat het lakwerk dat door de regeringsfunctionarissen in India werd besteld werd voldaan, moesten de opperhoofden van Deshima noodgedwongen het bevel van de gouverneur accepteren dat het gewenste lakwerk aanbesteed werd aan de hele groep die toestemming had om voor de Nederlanders te werken. ${ }^{11}$ In 1659 werd het uiteindelijk toegestaan dat de Nederlanders een contract konden afsluiten bij de lakwerkers van hun keus. ${ }^{12}$ Uit de bronnen wordt het overigens niet duidelijk of dit inderdaad de regel werd.Brill. come4/26/2023 12:52:31PM 


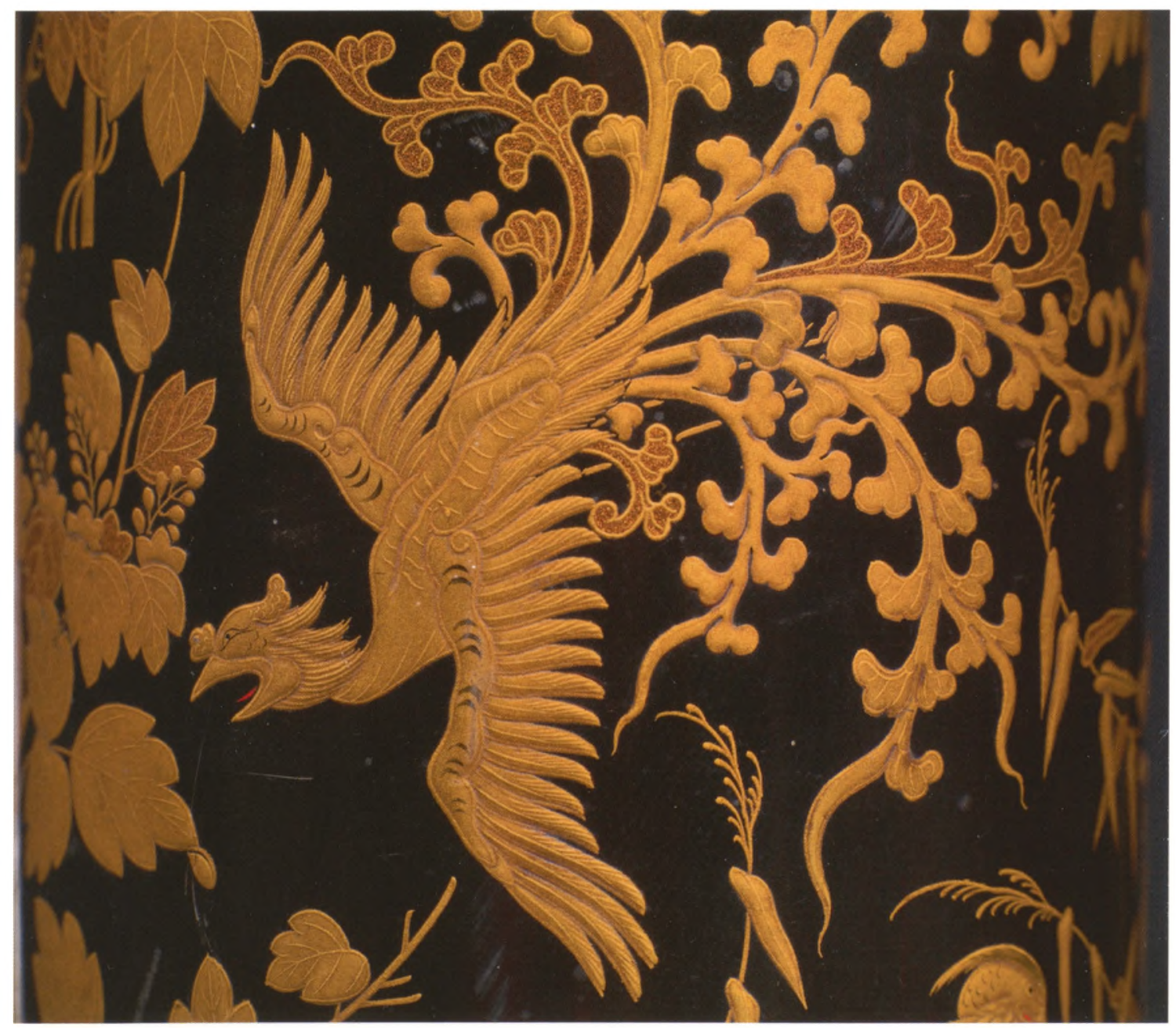

In 1675 en 1676 komen we weer een bij naam genoemde lakwerker tegen, Kiseijmon, alias Moute Cabessa, die het gedaan had weten te krijgen dat opperhoofd Johannes Camphuys bij hem lakwerk contracteerde, onder belofte dat hij 'uitnemend schoon en curieus' werk zou leveren. ${ }^{13}$ In 1684 bleek dezelfde Kisemon, ook bekend als Moeito Cabessa, niet alleen lakwerk te kunnen leveren, maar hij voorzag de Compagnie ook van koperplaten wanneer de koperhandelaars die niet wilden of konden maken. ${ }^{14}$ Bovendien schrok Mackia Kiseijmon er niet voor terug de opdracht aan te nemen tien paar schermen voor Bengalen te maken voor een lagere prijs dan die de gebruikelijke makers van schermen vroegen en die naar de mening van opperhoofd Constantijn Ranst de Jonge veel te hoog was. Ranst stelde wel de voorwaarde dat als de schermen niet aan de eisen zouden voldoen, hij ze zou weigeren. ${ }^{15}$ De oude meester-lakwerker toonde zich ook genegen om de stoffen die resteerden nadat de vereiste jaarlijkse geschenken waren $_{2023}$ 12:52:31PM overhandigd aan de shogun en hofdignitarissen in de hoofdstad Edo ia free access 
Gerrit van Goor, Portret van Johannes Camphuys (1634-1695), paneel, 1685, Rijksmuseum Amsterdam, SK-A-3768

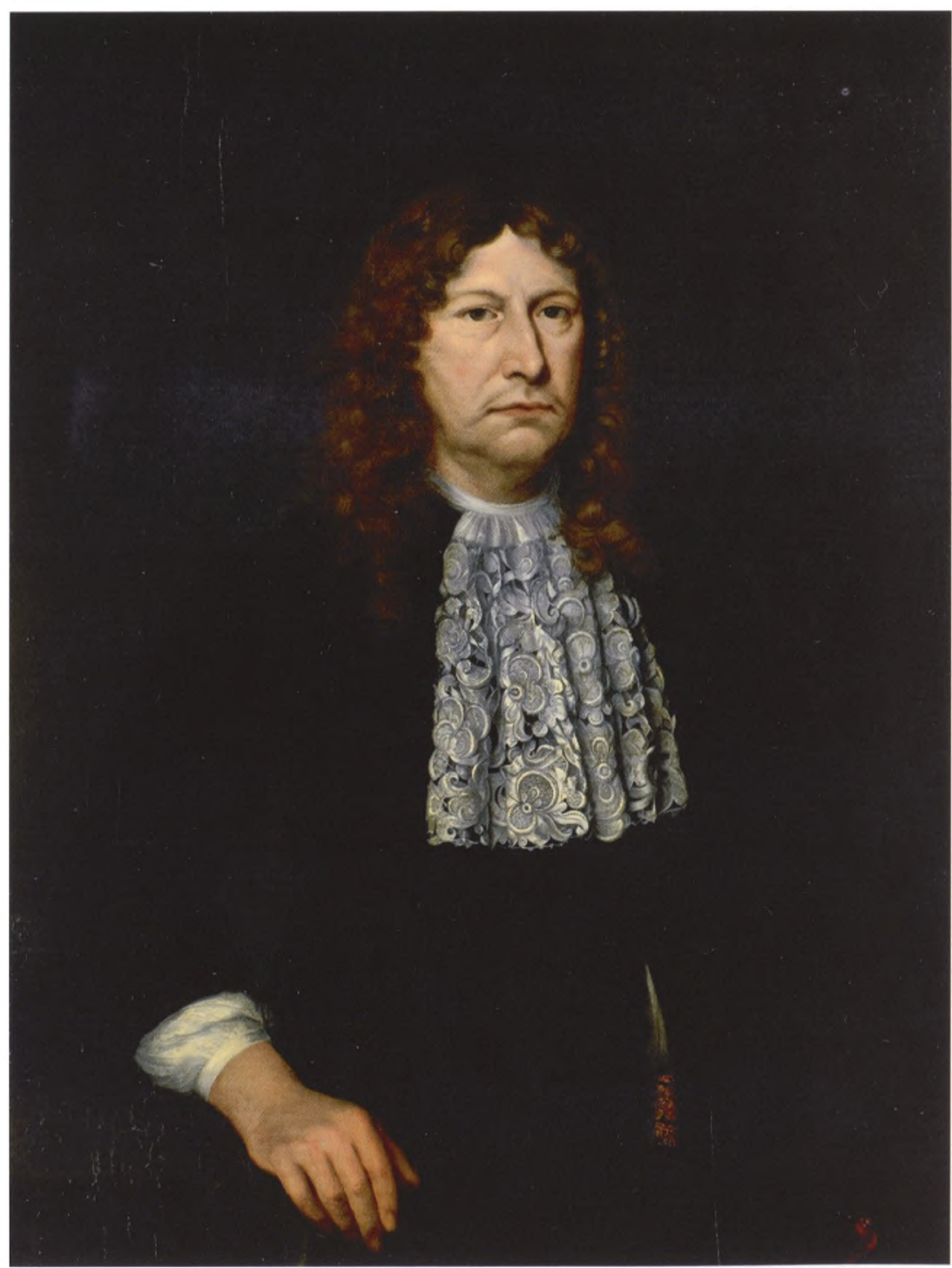

(tegenwoordig Tokio), over te nemen tegen betaling van goed gemaakt lakwerk of contant geld. ${ }^{10}$

Hendrick van Buijtenhem, die Ranst als opperhoofd opvolgde voor het handelsjaar $1684 / 5,{ }^{17}$ zijn eerste ambtstermijn, kreeg al meteen te maken met problemen bij de aanbesteding van de zes kabinetten die door de gouverneurgeneraal een jaar eerder voor Nederland waren besteld. De kwaliteit van de kabinetten die in 1684 werden afgeleverd, was beneden de maat en Ranst weigerde ze aan te nemen. Hij gaf Van Buijtenhem de opdracht een nieuwe aanbesteding te doen. ${ }^{18}$ Het lukte Van Buijtenhem niet een contract af te sluiten, omdat de lakwerkers - blijkbaar is Mackia Kiseijmon hier niet bij betrokken - voorgaven dat ze de kabinetten niet voor de gebruikelijke prijs van 100 teil $^{19}$ konden maken, maar de helft meer eisten. Van Buijtenhem besloot om te zien of hij de kabinetten inoMiyake, fwanneer hij deze stad $\mathrm{d}_{12: 52: 31 \mathrm{pM}}$ aandeed op weg naar Edo om eer te bewijzen aan de shogun, bij eerianfdereaccess 


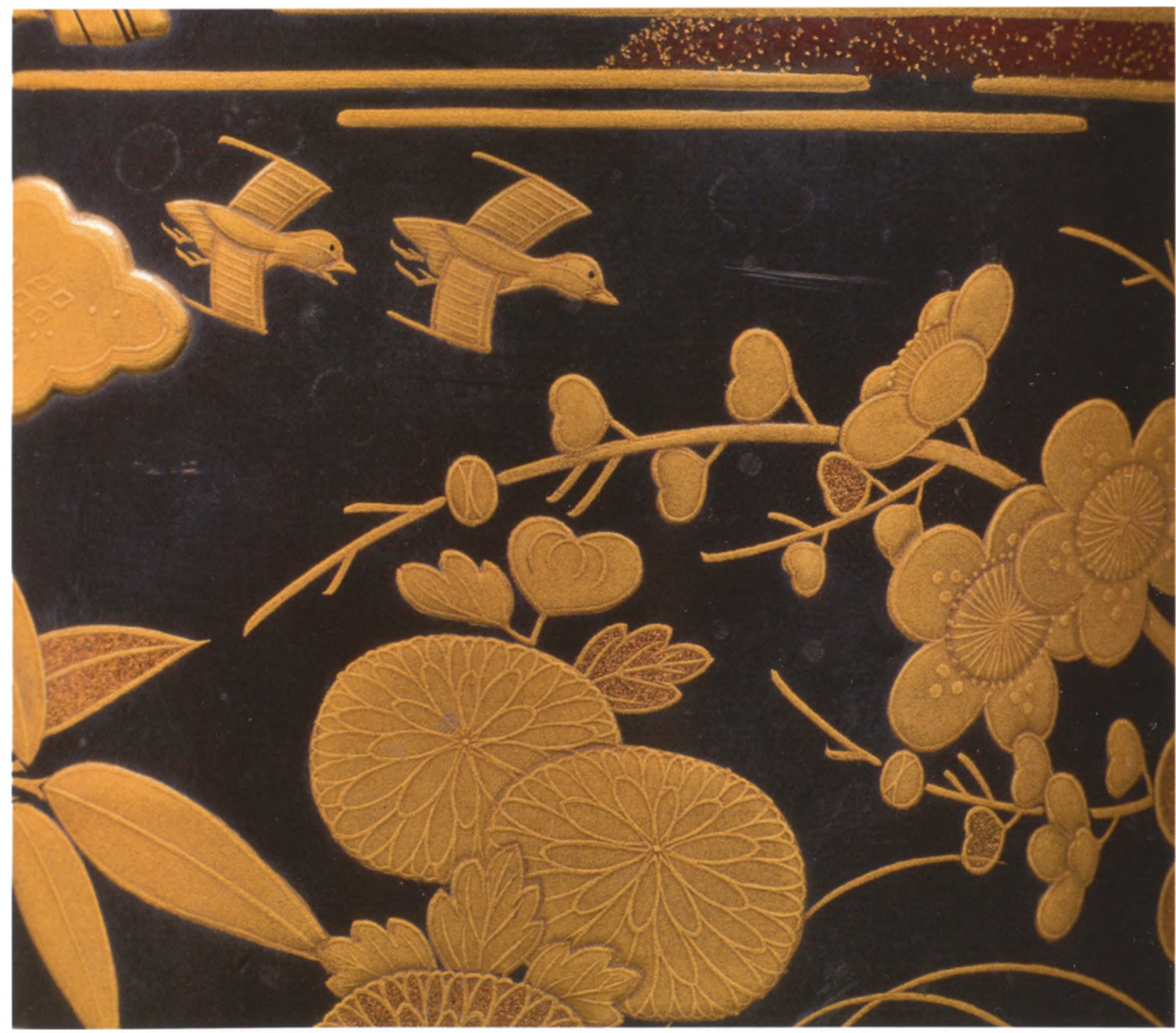

lakwerker zou kunnen aanbesteden. ${ }^{20}$ Op 15 maart 1685, toen hij in Miyako was, kwamen de lakwerkers om hem de monsters van de schrijfladen voor Bengalen die ze gereed hadden te tonen. Hij was er tevreden over, maar het lukte hem niet om de zes paren kabinetten aan te besteden. De lakwerkers vroegen 120 teil, wat Van Buijtenhem nog steeds te veel vond en hij besloot om te wachten tot de handelstijd wanneer er in de kramen op Deshima lakwerk werd aangeboden, in de hoop dat hij ze dan voor de gewone prijs van 100 teil zou kunnen kopen. ${ }^{21}$

Enkele maanden later bleek dat dit Van Buijtenhem niet gelukt was, want hij gaf zijn opvolger, Andreas Cleijer, opdracht om zes paar kabinetten aan te besteden. Dit zou hij moeten doen bij een nieuwe lakwerker, omdat de oude lakwerker Makia Kiseijmon, 'of anders in de wandeling Moeta Cabessa genaempt' was overleden. ${ }^{22}$ In één kopięvan zijn briefaan de gouverneun- 52:31pM generaal schrijft Van Buijtenhem dat de Compagnie 'wel over de 50 jareñee access 
Mackia Kiseijmon, alias Moete Cabessa, en Sirosaimon of Siroseijmon zijn dus de twee lakmeesters die - samen met hun knechts of kornuiten - ten tijde van Hendrick van Buijtenhems ambtsperiodes als opperhoofd van de Nederlandse factorij op Deshima de Compagnie van lakwerk voorzagen. Over Sirosaimon kregen we nagenoeg alleen maar klachten te horen van de opeenvolgende opperhoofden. Mackia Kiseijmon, daarentegen, was een beroemde lakwerker, die de Europese 'konst en swier' beheerste en al 40 of 50 jaar lakwerk aan de Compagnie had geleverd. Wanneer we terugrekenen, dan komen we op 1635 of 1645 . In 1635 en 1636 troffen we Mahia Siemon aan, die meer dan 1000 stuks lakwerk afleverde. In 1643 werd Mackina Sinsemon belemmerd in het afhandelen van zijn contract met de Compagnie door de jaloezie van andere lakwerkers. Zou het om dezelfde persoon gaan? Hoogstwaarschijnlijk wel. Het lakwerk waar hier sprake van is wordt deels omschreven als 'extraordinarie schoon verlakt'. In dit verband is de bijnaam van Kiseijmon, Moete Cabessa in zijn verschillende spellingen, interessant. Volgens mij staat Moete Cabessa voor het Portugese muito cabessa. Een van de $17^{\mathrm{e}}$-eeuwse handelstermen die in grote delen van Azië werden gebruikt om kwaliteit aan te duiden was het Portugese woord cabessa (hoofd) voor de beste kwaliteit. Muito is meest en muito cabessa zou dus zoiets betekenen als Mijnheer Allerhoogste Topkwaliteit. De extraordinaire schone kwaliteit van het lakwerk dat Mackina Sinsemon leverde zou hem deze mooie bijnaam bezorgd kunnen hebben.

We weten niet wanneer Hendrick van Buijtenhems lakkoker is gemaakt. Het zal waarschijnlijk zijn gemaakt in de jaren tussen zijn eerste aanstelling, $1684 / 5$, en zijn laatste, $1692 / 3$. De datum van zijn eerste aanstellingsbrief is 28 oktober 1684 . Op 14 november onderhandelde hij met de lakwerkers, al is het niet duidelijk of Kiseijmon daarbij betrokken was. Het overlijden van de laatste wordt op 31 juli gemeld en moet dus enige tijd daarvoor hebben plaatsgevonden. Zou er tijd genoeg zijn geweest om de lakkoker onder zijn leiding, of die van zijn zoons, te hebben laten maken? Mocht de koker door Siroseijmon of zijn kornuiten zijn gemaakt, dan logenstraft de goede kwaliteit van het lakwerk de vaak geuite klachten van de Nederlandse opperhoofden over de slechte kwaliteit van hun werk.

\section{Noten}

Afbeeldingen $2 \mathrm{t} / \mathrm{m}$ 6: Fries Museum, Erik en Petra Hesmerg

1. Zie O. Impey en C. Jörg, Japanese Export Lacquer 1580-1850, Amsterdam, 2005, p. 267.

2. Impey en Jörg, Op.cit. (noot 1), p. 32. In het originele dagregister staat Kitsibe en niet Kisibe, en het opperhoofd in dit handelsjaar is niet Frederik Coyett, zoals Impey en Jörg vermelden, maar Gabriel Happart. Zie C. Viallé en L. Blussé, The Deshima Dagregisters 1650-1660, Vol. XII (Intercontinenta no. 25), Leiden, 2005, p. 125, 22 nov. 1653. De opperhoofden van de Nederlandse factorij in Japan (Hirado en Deshima) hielden dagregisters bij van het reilen en zeilen van de factorij voor hun superieuren in Batavia en Nederland. Een bijna complete reeks vanaf 1633 tot 1860 van deze dagregisters is bewaard gebleven en maakt deel uit van het archief van de Nederlandse factorij in Japan in het Nationaal Archief, Den Haag. Een Engelse bewerking van de teksten wordt uitgegeven door het Instituut voor de Geschiedenis van de Europese Expansie van de Universiteit Leiden. 
3. Nationaal Archief (NA), het Archief van de Nederlandse factorij in Japan (NFJ), inv.nr. 276, Ontvangen brieven [in Hirado] 1614-1616, Osaka 25 nov. 1615, van Elbert Woutersz aan Jacques Specx.

4. NA, NFJ 276, Osaka 12 mei, Miyako 11 juni en Osaka 11 sept. 1616, Woutersz aan Specx. In deze bijdrage geef ik overal de spelling van de naam zoals die in de oorspronkelijke bron wordt weergegeven.

5. NFJ 835, Journaal, Hirado 12 nov. en 21 dec. 1635.

6. NFJ 836, Journaal, Hirado 26 sept. 1636.

7. NFJ 279, Jan van Elseracq aan Batavia, Gouverneur-generaal en Raden van Indië, Nagasaki 2 okt. 1642.

8. NFJ 279, Gouverneur-generaal en Raden aan Jan van Elseracq, Batavia 28 juni 1642.

9. NFJ 280, Jan van Elseracq aan Gouverneur-generaal en Raden, Nagasaki 1 okt. 1643.

10. NFJ 66, Japans dagregister Frederik Coyett, 16 nov. en 30 dec. 1652.

11. NFJ 286, Gouverneur-generaal en Raden aan Frederik Coyett, Batavia 21 juli 1653; NFJ 68, Japans dagregister Leonard Winnincx, 9, 10 en 12 nov. 1654.

12. NFJ 72, Japans dagregister Zacharias Wagenaer, 3 juni 1659.

13. NFJ 32, Memorie van overgave van Martinus Caesar aan Johannes Camphuys,

Nagasaki 7 nov. 1675; NFJ 89, Japans dagregister Johannes Camphuys, 31 jan. 1676.

14. NFJ 90, Japans dagregister Dirck de Haas, 19 apr. 1677.

15. NFJ 97, Japans dagregister Constantijn Ranst de Jonge, 22 maart 1684.

16. NFJ 97, Japans dagregister Ranst de Jonge, 8 mei 1684.

17. Op bevel van de Japanse regering moesten de opperhoofden van de Japanse factorij vanaf 1641 elk jaar verwisseld worden. De eenjarige ambtstermijn besloeg een handelsjaar en niet een kalenderjaar en begon op de 20e dag van de negende maand van de Japanse maankalender, wanneer het afgetreden opperhoofd volgens shogunaal bevel uit Nagasaki moest vertrekken.

18. NFJ 315, Constantijn Ranst de Jonge aan Gouverneur-generaal en Raden, Nagasaki 27 okt. 1684; NFJ 33, Memorie van overgave van Constantijn Ranst de Jonge aan Hendrick van Buijtenhem, 28 okt. 1684.

19. De gebruikte rekeneenheid voor de Nederlandse handel in Japan. De teil was in deze tijd 3,5 gulden waard.

20. NFJ 98, Japans dagregister Hendrick van Buijtenhem, 14 nov. 1684. De contracten werden gewoonlijk in Nagasaki afgesloten, nadat de lakwerkers de bestelde objecten hadden afgeleverd.

21. NFJ 98, Japans dagregister Hendrick van Buijtenhem, 15 maart 1685.

22. NFJ 33, Memorie van overgave van Hendrick van Buijtenhem aan Andreas Cleijer, Nagasaki 17 okt. 1685. Van Buijtenhem vermeldt het overlijden van 'den lackwercker Kiesemon, of anders in de wandeling Moeta Cabessa genaempt' op 31 juli 1685 in zijn dagregister. NFJ 98.

23. NFJ 316, Van Buijtenhem aan Gouverneur-generaal en Raden, Nagasaki 16 okt. 1685; hierin staat 50 jaar; in de kopieën in VOC 1408 en VOC 1415 staat 40 jaar.

24. NFJ 99, Japans dagregister Andreas Cleijer, 6 nov. 1685.

25. NFJ 318, Constantijn Ranst de Jonge aan Gouverneur-generaal en Raden, Nagasaki 24 okt. 1687.

26. NFJ 320, Cornelis van Outhoorn aan Gouverneur-generaal en Raden, Nagasaki 31 okt. 1689.

27. NFJ 103, Japans dagregister Balthasar Sweers, 13 nov. 1689.

28. NFJ 318, Constantijn Ranst de Jonge aan Gouverneur-generaal en Raden, Nagasaki 24 okt. 1687; NFJ 107, Japans dagregister Gerrit de Heere, 1 nov. 1693.

29. NFJ 107, Japans dagregister Gerrit de Heere, 2 nov. 1693. 